\title{
Profil dan Kinerja Usahatani Kangkung Darat (Ipomoea reptans) dalam Pola Diversifikasi dengan Padi Ciherang di Desa Abianbase, Kecamatan Mengwi, Kabupaten Badung
}

\author{
I MADE PUTRA ARIMBAWA, I WAYAN WIDYANTARA, \\ NI LUH PRIMA KEMALA DEWI \\ Program Studi Agribisnis Fakultas Pertanian Universitas Udayana \\ Jl. PB. Sudirman Denpasar 80232 \\ Email: putraarimbawa68@gmail.com \\ widyantaramkr@yahoo.com
}

\begin{abstract}
Profile and Performance of Dry-Land Spinach (Ipomoea reptans) Farming In Rice Ciherang Diversification Patten in Abianbase Village, Mengwi District, Badung Regency
\end{abstract}

This study aimed to determine the profile of dry-land spinach farming and to compare the dry-land spinach with rice ciherang views by income differences as well as differences outpouring of labor in the family Village Abianbase. The research method used was interview, observation, and direct documentation of 27 respondents selected intentionally. The analysis used was descriptive analysis and comparison analysis. The results based on the characteristics of the respondent of swamp dryland spinach farmers seen from the age of more interest from group of productive age and old age the average education level of famers dry-land spinach elementary school graduates, amount of children's farmer an average had two late and second job as an average farmer laborers pelvis. Based on profit farming swamp dry-land spinach views of land area average used by 8 are, the total average cost of Rp. $389.694,11 /$ are with income Rp. 250.105,89/are and the value of $\mathrm{R} / \mathrm{C}$ ratio of 1,64 or worth to developing. Based on comparative analysis of fevenue swamp dry-land spinach with rice which is the average income of dry-land spinach Rp. 250.105,89/are and the average income of the rice is Rp. 147.956,63/are, while based a comparative analysis of the outpouring of labor in the family swamp dryland spinach amounting to $11,00 \mathrm{HOK} /$ are and rice at 1,02 HOK/are.

Keywords: profile, performance, dry-land spinach, rice plant

\section{Pendahuluan}

\subsection{Latar Belakang}

Indonesia sebagai negara agraris memandang perlu adanya upaya-upaya pengembangan dan peningkatan produksi komoditas dibidang pertanian, seperti 
diketahui hampir 60\% penduduk Indonesia berada di pedesaan dan bekerja sebagai penggarap lahan pertanian sawah (Bakir dkk dalam Siregar, 2008).

Lahan yang luas dan subur yang dimiliki negara Indonesia, menjadikan pertanian sebagai lahan yang memiliki nilai ekonomi. Sektor pertanian memegang peranan yang sangat strategis dalam penghasil bahan pangan seperti : beras, kedelai, jagung, buah-buahan dan sayur-sayuran (Bellinda, 2010).

Kondisi ini dapat ditunjukkan dari banyaknya penduduk yang bekerja pada sektor pertanian. Pada tahun 2000-an sekitar 55\% populasi tenaga kerja Indonesia bekerja di bidang pertanian. Pembangunan pertanian diharapkan selalu memberikan perhatian yang lebih besar pada potensi kawasan dan kapasitas warga masyarakat yang mendiami wilayah tersebut dan pemberdayaan pada kelompok masyarakat tani sangat diperlukan terutama mereka yang berada pada daerah tertinggal sehingga mereka dapat menjadi petani-petani, institusi yang mandiri, tangguh dalam mendukung pembangunan pertanian (Suratiyah, 2006).

Salah satu tujuan pembangunan pertanian selain untuk meningkatkan produktivitas lahan dan tanaman adalah untuk meningkatkan pendapatan dan kesejahteraannya. Upaya peningkatan pendapatan petani dapat bersumber dari usahatani padi dan non-padi, seperti palawija dan sayuran dengan pola diversifikasi (Khairina, 2006).

Petani telah memulai untuk mencoba mengusahakan berbagai komoditas yang memiliki keuntungan ekonomis tinggi selain mengusahakan tanaman padi di lahan sawahnya. Komoditas jagung manis, semangka, cabe, mentimun, terong, dan tanaman hortikultura lainnya menjadi pilihan bagi petani setelah mereka memanen padinya. Pilihan komoditas ini ditunjukkan untuk meningkatkan penerimaan usahatani sawah dalam satu tahun pertanian (Guntoro, 1995).

Pulau Bali yang berkembang sebagai daerah tujuan pariwisata utama di Indonesia, sebagian besar penduduknya merupakan masyarakat petani yang hidupnya banyak bergantung di sektor pertanian. Seiring dengan pesatnya kemajuan daerah Bali dibidang pariwisata, mendorong banyak berdirinya hotel, restoran dan rumah makan yang membutuhkan berbagai macam sayuran segar. Kondisi ini berimbas pula terhadap meningkatnya permintaan masyarakat pada sayuran. Kondisi ini menyebabkan banyak desa-desa di Bali mengembangkan tanaman sayur-sayuran untuk di produksi di lahannya.

Kabupaten Badung memiliki potensi wilayah yang cukup baik untuk mengembangkan usahatani sayur-sayuran, namun masih banyak permintaan sayursayuran yang belum terpenuhi dan bahkan harus dibeli dari luar daerah. Melihat peluang tersebut banyak Kecamatan di Kabupaten Badung melakukan pengalihan lahan untuk menanam sayur-sayuran salah satunya adalah Kecamatan Mengwi. Kecamatan Mengwi merupakan daerah pertanian persawahan dengan kontur tanahnya cukup gembur, basah, sistem irigasi baik, dan sumber air mengalir sepanjang tahun menyebabkan para petani dengan mudah menentukan beberapa alternatif dalam kegiatan pertaniannya. 
Beberapa petani di Desa Abianbase memanfaatkan lahan pertanian sawah dari tanaman padi ciherang dialihkan ke komoditi lain berupa tanaman sayuran, yaitu tanaman kangkung darat. Letak Desa Abianbase berada dekat dengan perkotaan yang banyak terdapat pasar-pasar tradisional dan daerah pariwisata yang tentunya memerlukan sayuran segar setiap hari. Pemasaran tanaman kangkung darat di Desa Abianbase akan jauh lebih mudah dibandingkan dengan desa-desa yang lain yang letaknya jauh dari perkotaan. Berdasarkan hal itulah biaya transportasi bisa ditekan sekecil mungkin dan mendapatkan keuntung yang optimal.

\subsection{Tujuan Penelitian}

Penelitian ini bertujuan untuk mengetahui profil usahatani kangkung darat di Desa Abianbase, Kecamatan Mengwi, Kabupaten Badung dan mengetahui perbandingan kangkung darat dengan padi ciherang dilihat dari perbedaan pendapatan dan curahan tenaga kerja dalam keluarga di Desa Abianbase, Kecamatan Mengwi, Kabupaten Badung.

\section{Metodologi Penelitian}

\subsection{Lokasi dan Waktu Penelitian}

Metode penentuan daerah penelitian diambil secara sengaja atau purposive samplingyaitu pengambilan obyek dengan sengaja didasarkan atas kriteria atau pertimbangan tertentu. Tempat penelitian ini dilakukan diDesa Abianbase, Kecamatan Mengwi, Kabupaten Badung. Penelitian dimulai dari bulan November 2015 s.d Januari 2016.

\subsection{Jenis dan Sumber Data Penelitian}

Jenis data penelitian terdiri atas data kualitatif dan data kuantitatif.Data kualitatif adalah data yang disuguhkan dalam bentuk dua parameter abstrak (Sukandarrumi, 2006). Data kualitatif dalam penelitian ini yaitu data berupa deskripsi dan penjelasan mengenai alasan petani memilih usahatani kangkung darat dalam pola deserfikasi dengan padi. Data kuantitatif yang diperoleh adalah data berupa angka, gambar atau grafik seperti umur, tingkat pendidikan, pekerjaan sampingan, curahan tenaga kerja, struktur biaya, luas lahan, produksi usahatani, dan pendapatan usahatani.

Sumber data penelitian terdiri atas dua jenis yaitu data primer dansekunder. Data primer, merupakan data penelitian yang diperoleh secara langsung dari sumber asli atau tidak melalui media perantara (Fauzi, 2009). Data sekunder, merupakan sumber data penelitian yang diperoleh peneliti secara tidak langsung melalui media perantara atau diperoleh dan dicatat oleh pihak lain (Fauzi, 2009). 


\subsection{Teknik Pengumpulan Data, Responden Penelitian dan Variabel Pengukuran}

Teknik pengumpulan data yang digunakan dalam penelitian ini yaitu wawancara, obeservasi, dokumentasi, dan studi pustaka. Responden penelitian pada penelitian ini terdiri atas 27 orang petani yang menanam kangkung darat dan padi pada satu lahan. Variabel dapat diartikan segala sesuatu yang akan menjadi objek pengamatan penelitian, atau faktor-faktor yang berperan dalam peristiwa atau gejala yang akan diteliti (Suryabrata, 2012). Variabel pengukuran pada penelitian ini terdiri atas perbandingan pendapatan dan perbandingan curahan tenaga kerja dalam keluarga usahatani kangkung darat dengan padi ciherang.

\subsection{Metode Analisis Data}

Metode analisis data yang digunakan dalam penelitian ini adalah dengan menggunakan metode deskriptif untuk menjawab tujuan pertama yaitu profil usahatani kangkung darat dan analisis perbandingan untuk menjawab tujuan kedua yaitu perbandingan usahatani kangkung darat dengan usahatani padi. Menurut Robert dan James (1960) uji dua sampel dilakukan dalam tiga tahapan yaitu, tahapan pertama adalah menguji apakah varian dari kedua populasi bisa dianggap sama atau tidak, tahap kedua menentukan rumus Uji T yang ditentukan dengan Uji F, dan tahap ketiga analisis Uji $\mathrm{T}$ untuk melihat ada tidaknya perbedaan rata-rata antara dua sampel. Tahap pertama mencari nilai varians pendapatan usahatani kangkung darat dan padi dengan rumus :

$$
\sigma^{2}=\sum_{i=1}^{n}\left(\mathrm{X}_{\mathrm{i}}-\overline{\mathrm{X}}\right)^{2}
$$

$$
\text { Keterangan : } \begin{aligned}
\sigma^{2} & =\text { Varians usahatani } \\
\bar{X} i & =\text { Nilai X ke- } i \\
\bar{X} & =\text { Rata-rata pendapatan/curahan tenaga kerja usahatani }
\end{aligned}
$$

Tahap selanjutnya menentukan rumus $\mathrm{T}$ hitung yang digunakan dengan analisis perbandingan dengan rumus :

$$
\mathrm{F} \square=\frac{\text { Varians terbesar }}{\text { Varians terkecil }}
$$

Jika $\mathrm{F} \square<$ Ftabel $(0,05)$, maka varians Homogen

Jika $\mathrm{F} \square>$ Ftabel $(0,05)$, maka varians Heterogen 
a. Jika varians Homogen, maka uji t dilakukan rumus :

$$
\mathrm{t}=\frac{\bar{X}_{1}+\bar{X}_{2}}{\sqrt{\frac{\left(n_{1}-1\right) S_{1}^{2}+\left(n_{2}-1\right) S_{2}^{2}}{n_{1}+n_{2}-2}\left(\frac{1}{n_{1}}+\frac{1}{n_{2}}\right)}}
$$

b. Jika varians Heterogen, maka uji t dilakukan rumus :

$$
\mathrm{t}=\frac{\bar{X}_{1}+\bar{X}_{2}}{\sqrt{\frac{S_{1}^{2}+S_{2}^{2}}{2 n}}}
$$

Keterangan : $\bar{X}_{1}=$ rata-rata pendapatan/curahan tenaga kerja kangkung darat

$\bar{X}_{2}=$ rata-rata pendapatan/curahan tenaga kerja padi ciherang

$n_{1}=$ jumlah petani kangkung darat

$n_{2}=$ jumlah petani padi ciherang

$S_{1}^{2}=$ standar deviasi kangkung darat

$S_{2}^{2}=$ standar deviasi padi ciherang

Hipotesis (dugaan) yang digunakan :

$\mathrm{H}_{0}$ : Tidak terdapat perbedaan antara rata-rata pendapatan/curahan tenaga kerja usahatani kangkung darat dengan padi.

$\mathrm{H}_{1}$ : $\quad$ Terdapat perbedaan antara rata-rata pendapatan/curahan tenaga kerja usahatani kangkung darat dengan padi.

Dasar pengambilan keputusan :

Menggunakan perbandingan antara t hitung dengan $\mathrm{t}$ tabel

- jika thitung > t tabel ; maka $\mathrm{H}_{0}$ ditolak, $\mathrm{H}_{1}$ diterima

- jika t hitung < t tabel ; maka $\mathrm{H}_{1}$ diterima, $\mathrm{H}_{0}$ ditolak

\section{Hasil dan Pembahasan}

\subsection{Karakteristik Responden}

Berdasakan dari umur menurut Ananta dan Anwar (1994) struktur umur dibedakan menjadi tiga kelompok, yaitu a) kelompok umur muda, dibawah 15 tahun, b) kelompok umur produktif, usia 15 sampai dengan 64 tahun, dan c) kelompok umur tua, usia 65 tahun ke atas, responden jumlah responden terbanyak berada pada kelompok umur produktif sebanyak 25 orang atau 92,59\%, sedangkan tingkat pendidikan terakhir responden tamatan SD sebanyak 19 orang $(70,37 \%)$ responden, berdasarkan jumlah anak bahwa dari total ke 27 responden memiliki rata-rata2 orang anak sebesar $70,37 \%$, dan berdasarkan pekerjaan sampingan sebagian besar petani 
responden memiliki pekerjaan sampingan sebagai buruh panggul yaitu sebanyak $33,33 \%$.

\subsection{Profil dan Kinerja Petani Responden Kangkung Darat}

Berdasarkan luas lahan yang diperuntuhkan untuk kangkung darat kisaran delapan sampai sepuluh are. Curahan tenaga kerja yang digunakan lebih banyak menggunakan tenaga kerja dalam keluarga terutama dalam panen hasil produksi kangkung darat. Biaya rata-rata yang dikeluarkan untuk usahatani kangkung darat dalam enam bulan sebesar Rp. 389.694,11/are yang tidak begitu besar mengingat lahan yang dipakai untuk menanam kangkung darat tidak membutuhkan lahan yang luas dan menghasilkan penerimaan rata-rata sebesar Rp. 639.800,00/are yang relatif besar, hal tersebut terjadi karena produksi tanaman kangkung darat yang sangat cepat yang hanya membutuhkan waktu dua hari sudah mampu dipanen. Pendapatan petani kangkung darat yang didapatkan rata-rata sebesar Rp. 250.105,89/are relatif besar, karena itulah 27 petani yang melihat peluang yang sangat besar ini akan terus mengembangkan tanaman kangkung darat dan melebarkan pemasarannya. Berdasarkan analisi $\mathrm{R} / \mathrm{C}$ ratio didapatkan sebesar 1,64, yang artinya usahatani kangkung darat layak untuk dikembangkan.

\subsection{Analisis Perbandingan Pendapatan}

Berdasarkan analisis perbandingan dengan uji t, rata-rata pendapatan kangkung darat adalah sebesar Rp. 205.105,89 dan padi sebesar Rp. 147.956,63 dari perbedaan pendapatan tersebut dilakukan pengujian secara statistik. Berdasarkan uji F data pendapatan usahatani kangkung darat dengan padi memiliki varians heterogen, dengan demikian untuk melihat adanya perbedaan menggunakan uji t. Berdasarkan perhitungan manual uji $\mathrm{t}$, diperoleh nilai $\mathrm{t}$ hitung sebesar 43,34 dan $\mathrm{t}$ tabel 2,060. Nilai t hitung lebih besar dari t tabel, yang berarti $\mathrm{H}_{0}$ ditolak, Hiditerima. Hipotesis (dugaan) yang dapat digunakan dari penilaian uji beda dengan program SPSS dan uji t manual adalah terdapat perbedaan antara rata-rata pendapatan usahatani kangkung darat dengan padi.

\subsection{Perbandingan curahan tenaga kerja dalam keluarga}

Berdasarkan analisis perbandingandengan uji t. Rata-rata curahan tenaga kerja dalam keluarga kangkung darat adalah sebesar 11,00 HOK dan padi sebesar 1,02 HOK dari perbedaan curahan tenaga kerja dalam keluarga tersebut dilakukan pengujian secara statistik. Berdasarkan uji $\mathrm{F}$ data curahan tenaga kerja dalam keluarga usahatani kangkung darat dengan padi memiliki varians heterogen, demikian untuk melihat adanya perbedaan menggunakan uji t. Berdasarkan perhitungan manual uji t, diperoleh nilai t hitung sebesar 54,23 dan t tabel 2.060. Nilai thitung lebih besar dari t tabel, yang berarti Ho ditolak, Hiditerima. Hipotesis (dugaan) yang dapat digunakan dari penilaian uji beda dengan program SPSS dan uji 
t manual adalah terdapat perbedaan antara rata-rata curahan tenaga kerja dalam keluarga usahatani kangkung darat dengan padi.

\section{Simpulan dan Saran}

\subsection{Simpulan}

Berdasarkan uraian hasil penelitian, dapat ditarik kesimpulan bahwa profil usahatani kangkung darat di Desa Abianbase dengan luas lahan yang sempit, dengan rata-rata biaya yang kecil sebesar Rp. 389.694,11/are namun mendapatkan pendapatan rata-rata sebesar Rp. 250.105,89/are. Usahatani kangkung darat sangat layak diteruskan karena menurut analisis $\mathrm{R} / \mathrm{C}$ ratio menunjukkan lebih dari satu yaitu sebesar 1,64. Berdasarkan analisis perbandingan pendapatan usahatani kangkung darat menunjukkan rata-rata pendapatan sebesar Rp. 250.105,89/are, sedangkan ratarata pendapatan usahatani padi sebesar Rp. 147.956,63/are. Berdasarkan perhitungan manual uji t, diperoleh nilai t hitung sebesar 43,34 dan t tabel 2,060. Nilai t hitung lebih besar dari t tabel, yang berarti $\mathrm{H}_{0}$ ditolak, Hiditerima artinya dalam hal pendapatan kangkung darat terdapat perbedan antara pendapatan padi. Analisis perbandingan usahatani dalam penggunaan curahan tenaga kerja dalam keluarga menunjukkan usahatani kangkung darat lebih banyak memakai tenaga kerja dalam keluarga yaitu 11,00 HOK/are dibandingkan dengan usahatani padi sebesar 1,02 HOK/are. Berdasarkan perhitungan manual uji t, diperoleh nilai $t$ hitung sebesar 54,23 dan t tabel 2.060. Nilai thitung lebih besar dari t tabel, yang berarti $\mathrm{H} 0$ ditolak, H1diterima artinya terdapat perbedaan antara rata-rata curahan tenaga kerja dalam keluarga usahatani kangkung darat dengan padi.

\subsection{Saran}

Saran yang dianjurkan adalah supaya petani usahatani kangkung darat di Desa Abianbase lebih memperluas lahan kangkung darat untuk memenuhi permintaan yang semakin banyak dan mendapatkan keuntungan yang lebih besar, namun tidak menghilangkan tradisi akan menanam tanaman padi.

\section{Ucapan Terima Kasih}

Puji syukur penulis panjatkan kepada Tuhan Yang Maha Esa atas berkat dan kasih-Nya, penulis dapat menyelesaikan penelitian ini. Penelitian ini tidak mungkin terlaksana bahkan tercapai tanpa adanya partisipasi dari berbagai pihak. Maka dari itu, pada kesempatan ini penulis menyampaikan ucapan terima kasih kepada seluruh pihak yang telah membantu penelitian ini sehingga penelitian ini dapat terselesaikan dengan baik.

\section{Daftar Pustaka}

Ananta, A. dan Anwar E. 1994. ProyeksiPendudukdanAngkatanKerja di Indonesia 1995-2025. LembagaDemografi, FakultasEkonomi, Universitas Indonesia. Jakarta. 
Bellinda, Alit Fajar. 2010. Analisis Usahatani Tembakau Rakyat Desa Danurejodi Kabupaten Temanggung Jawa Tengah. [Skripsi]: Fakultas Pertanian.

Fauzi, Mochamad. 2009. Metode Penelitian Kuantitatif, Sebuah Pengantar.PenerbitWalisongo Press. Semarang.

Guntoro, Suprio. 1995. Panca Pesona Wisata Agro Daerah Bali. Yayasan Bina Hayati. Denpasar.

Kharina, Y. 2006. Analisis Pendapatan Usahatani dan Pemasaran Wortel dengan Budidaya Organik (Studi Kasus : Desa Citeko, Kecamatan Cisarua, Bogor). [Skripsi]: Fakultas Pertanian. Universitas Bogor.

Siregar, FM. 2008. Analisis Usahatani Cabai Merah Organik (Studi Kasus : Kelompok Tani "Kaliwung Kalimuncar" Desa Tugu Utara, Kecamatan Cisarua, Bogor). [Skripsi]: Fakultas Pertanian. Institut Pertanian Bogor.

Robert, Steel G.D dan James H. Torrie. 1960. Principles and Procedures of Statistics. McGrow-Hill Book Comp. New York.

Sukandarrumi. 2006. Metodologi Penelitian, Petunjuk Praktis Untuk Penelitian Pemula. Penerbit Gadjah Mada University Press. Yogyakarta.

Suratiyah, K. 2006. Ilmu Usahatani. Penebar Swadaya, Jakarta.

Suryabrata, Sumadi. 2012. Metodologi Penelitian. PT Raja Grafindo Persada. Jakarta. 